\title{
Histopathology Quiz
}

M.A.D.N. Munasinghe, P.G.A.N. Jayathilaka, S. J. De. S Hewavisenthi

Department of pathology, Faculty of Medicine, University of Kelaniya, Sri Lanka

\section{Case History}

A 42-year-old woman presented with heavy menstrual bleeding and chronic pelvic pain for three months duration. She had been treated with norethisterone. As she did not response to the medical treatment she underwent hysterectomy, bilateral salpingectomy and right oophorectomy.

\section{Macroscopy}

We received a uterus with cervix measuring $90 \times 60 \times 40 \mathrm{~mm}$. The endometrium was irregular and polypoidal in appearance. The endometrial thickness ranged from 3 to 10 $\mathrm{mm}$. The myometrial thickness was $30 \mathrm{~mm}$ and showed multiple fibroids. Gross appearance of both tubes and the right ovary was normal.

Given below are the photomicrographs of the representative sections from the endometrium.

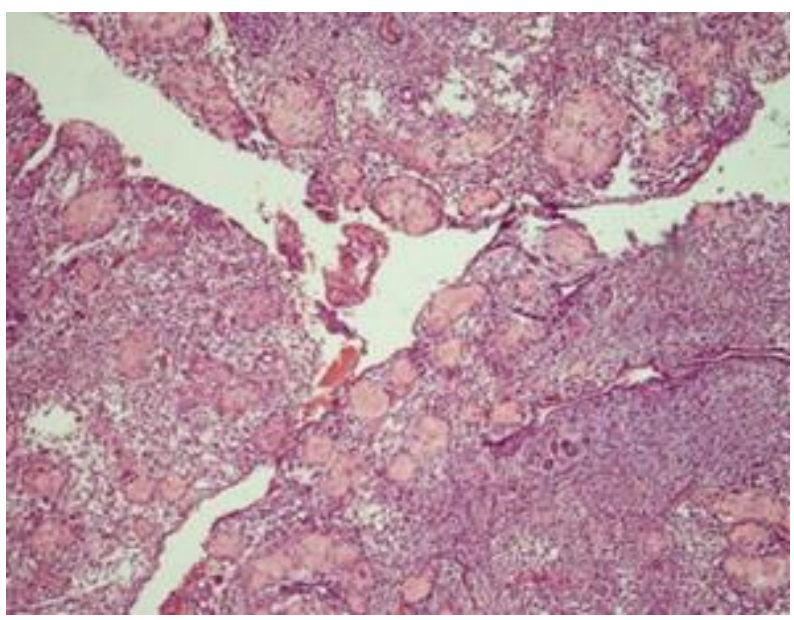

Figure 1: A sections of the endometrium ( $H \& E \times 100)$

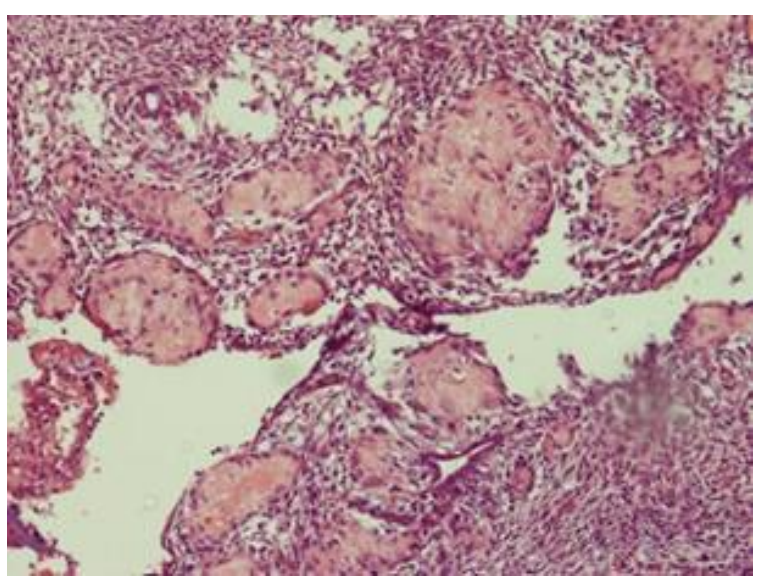

Figure 2; A section of the endometrium ( $H$ \& E x200)

1. What is your diagnosis /differential diagnosis?

2. What are the ancillary tests you would perform?

See page 36-38 for the answer to quiz and discussion. 